\section{Genetic testing, biotechnology, and GMOs: A snapshot of public opinion, 2003 through 2004}

\section{To the Editor:}

The Living Genome: Reading the Book of Life was a 3000 square foot genetics/genomics exhibit at the Houston $\mathrm{Mu}$ seum of Natural Science. ${ }^{1}$ The exhibit ran from April 2003 to November 2004. Three computer kiosk type polling stations, positioned at the exit from the exhibit, invited visitors to respond to 24 questions on topics in genetics and genomics. The polling stations were available for the first 13 months of the exhibit. The polling stations used the survey program portion of the Museums Teaching Planet Earth Software Suite, developed through a NASA cooperative agreement with the Rice Space Institute of Rice University and the Houston Museum of Natural Science. The software facilitates four stem surveys in which questions are followed by four possible responses. Each polling station asked two demographic questions: age group (18 and under; 19-30; $31-55$; or 56 or over) and gender, with or without a science background (male/science background; male/no science background; female/science background; or, female/no science background). These two demographic questions were followed by eight topical questions relating to genetic testing and personal genetic information (Polling Station 1), genetic technologies (Polling Station 2), or genetically modified organisms (Polling Station 3). Responses to the polling station questions were imported into Microsoft Excel spreadsheets and analyzed for overall response rates to each question and answer, and according to age, gender, and self-assessed science background of respondents using the Web Chi Square Calculator from the Department of Linguistics at Georgetown University ${ }^{2}$ (online Table 1, available at http://www.geneticsinmedicine.org).

Except for the small number of respondents over the age of 55, there was roughly an even distribution of respondents among the other age groups and between gender and science background categories (Fig. 1). Age and gender were the most significant factors in answer selection. Age was a statistically significant factor in answering all questions except one: Would you agree to have your child tested for genetic disease? Gender was a statistically significant factor in answering all questions except three: (1) Imagine that you have a gene for a disease that will not make you sick for 20 years. Should your insurance company know about this?; (2) Would you agree to have your child tested for genetic disease?; and, (3) Do you support human stem cell research to discover new treatments for diseases? Science background showed statistical significance for only 13 of 24 questions. Because determination of science background was self-assessed, the reduced significance of this factor in answer selection may reflect respondent-based variability in what was considered to be a science background.

Of the eight topical questions in each polling station, the median number of questions answered by respondents was eight. Notable findings of the polling station questions included:

- There was a greater propensity for women and adults of child-bearing age to agree to a genetic test for the purpose of understanding genetic risk for themselves and their relatives, regardless of whether the test was diagnostic or presymptomatic.

- There was greater concern about genetic discrimination in insurance among people over age 19 and in employment among people over age 31 .

- Individuals aged 19 to 55 were more likely to advocate required informed consent for genetic tests.

- $30 \%$ of males found nontherapeutic uses of gene therapy acceptable; $17 \%$ of females did.

- 58\% of individuals aged 18 or under found human cloning acceptable.

- Males were less likely than females to be concerned with the environmental impact or safety of genetically modified organisms/foods.

Samplings of public opinion provide an indication of public attitudes and concerns related to genetic and genomic technologies and permit evaluation of how public attitudes change over time. Public opinion polls also inform policy decisions and appropriation of resources. Such polls require continued sampling over time and rigorous scientific evaluation. Although little is known about the individual respondents represented in this study, these data provide a snapshot of popular opinion on a variety of topics in genetics and genomics in the years 2003 through 2004 Comparison of this polling data to data from other geographic regions of the United States, or the world, would be of interest and may provide guidance for future studies better suited to more rigorous public opinion polling on topics in genetics and genomics.

\section{ACKNOWLEDGMENTS}

The Living Genome: Reading the Book of Life exhibit was funded by Lead Donors Applera Charitable Foundation, The Gordon and Mary Cain Foundation, E. I. duPont de Nemours and Company, and Hewlett-Packard Company. Major Contributors included Amersham Biosciences, Beckman Coulter, Pall Corporation, PerkinElmer Foundation, Sigma-Aldrich Corporation, SeqWright, Inc., Gilbane Building Company, the Baylor College of Medicine Human Genome Sequencing Center, and the Baylor College of Medicine Department of Molecular and Human Genetics. Supporters included BD Discovery Labware, Ladd Photography/Houston, EMD Chemicals, Inc., and VWR International, Inc. Development of the survey software was funded by NASA's Office of Earth Science under cooperative agreement NCC5-311. The authors thank Renee Davis of the Houston Museum of Natural Science for her support of this project and Aletta Moore of The Bobby R. Alford Department of Otorhinolaryngology and Communicative Sci- 
Self-reported Science Background: 53\%

\author{
Gender: $55 \%$ Female \\ $45 \%$ Male
}

\section{References}

1. Alford RL, Sumners C, Wright S, Henderson K, Maxwell C, Gassmann D et al. The Living Genome: Reading the book of life: A model for community-based genetics education. Biol Digest 2004;31:10-17.

2. Ball CN, Connor-Linton J Web Chi Square Calculator. Department of Linguistics, Georgetown University. Available at: http://www.georgetown.edu/faculty/ballc/ webtools/web_chi.html. Accessed August 2, 2004.

Fig. 1. Demographics of polling station respondents. Self-assessed science background, gender, and age of respondents are shown, as percentages of the whole group.

ences, Baylor College of Medicine for critical evaluation of this manuscript.

Raye L. Alford, PhD The Bobby R. Alford Department of Otorhinolaryngology and Communicative Sciences Baylor College of Medicine Houston, Texas

Kelley E. Morris, C. Michelle Rives, Steven E. Scherer, PhD, George Weinstock, PhD, Richard A. Gibbs, PhD

The Human Genome Sequencing Center Department of Molecular and Human Genetics Baylor College of Medicine Houston, Texas

Karim Ghonima Mark Belcher, Hayden Valdes,

Carolyn Sumners, PhD

The Houston Museum of Natural Science Houston, Texas

Colin Law, PhD

Department of Physics and Astronomy Rice University Houston, Texas

Patricia Reiff, PhD

Department of Physics and Astronomy Rice Space Institute Rice University Houston, Texas 